\title{
FLOOD RISK ASSESSMENT AND PRIORITISATION OF MEASURES: TWO KEY TOOLS IN THE DEVELOPMENT OF A NATIONAL PROGRAMME OF FLOOD RISK MANAGEMENT MEASURES IN MOLDOVA
}

\author{
E. FRANK ${ }^{1}$, D. RAMSBOTTOM ${ }^{2} \&$ A. AVANZI ${ }^{1}$ \\ ${ }^{1}$ BETA Studio srl, Italy. \\ ${ }^{2} \mathrm{HR}$ Wallingford Ltd, UK.
}

\begin{abstract}
Following severe floods in 2008 and 2010, the Government of Moldova requested assistance to improve flood protection throughout the country. The European Investment Bank has funded a Technical Assistance project to develop a programme of flood risk management measures. The project included the detailed 2D hydraulic modelling of the high-risk rivers (about $3400 \mathrm{~km}$ ) to produce flood hazard and flood risk maps, the identification of measures to reduce the flood risk, the prioritisation of measures and the development of a phased investment programme and a Short-Term Investment Plan. Flood risk was assessed using 12 flood risk indicators representing social, economic and environmental impacts of flooding. Prioritisation of measures took account of: (i) the urgency of the measure; (ii) the magnitude of the risk that can be reduced with the measure; (iii) the benefit-cost ratio of the measure. The approaches used and in particular the methodologies implemented and the results obtained for flood risk assessment and for prioritisation of measures proved to be valuable tools to reach the objective of the study and, in particular, to facilitate the discussion with the stakeholders and the decision-making process.
\end{abstract}

Keywords: flood management, flood risk assessment, hydraulic modelling, measures, national programme.

\section{INTRODUCTION}

Flooding of river systems is one of the most frequent and costly natural hazard affecting the majority of the world's countries on a regular basis [1].

Analysis of past flood events shows that the majority of losses arise in urban areas, due to damages of structures, costs of business shut-down and failure of infrastructure [2, 3].

Consequences of flooding, or damages, are usually divided in two classes, tangible and intangible damages, depending on the possibility of assessing them in monetary terms. A further classification distinguishes losses in direct and indirect damages, with the first resulting from the physical contact of water with exposed elements and the second induced by the flood, but occurring, in space and time, outside the event [4-6]. Even though it is acknowledged that intangible and indirect damages can have an important contribution in total flood damage, a large part of the literature is focused only on direct tangible damages.

Insurance companies and research institutions in many countries develop and use flood damage models to assess the expected flood impact in economic terms. 
The contribution of damage modelling is becoming of essential importance in the field of flood risk management, for decision-making processes and for developing flood control policies and strategies. This role has been emphasised by the European Floods Directive [7], which requires Member States to prepare floods risk maps and to establish flood risk management plans focused on prevention, protection and preparedness, taking also into account cost-benefit aspects (e.g. related to the implementation of flood mitigation measures). This means that the 'classical' concept of flood protection, based on design standards related to predefined return periods, is increasingly being replaced by more comprehensive understanding of the risk over a certain period $[8,9]$.

This paper describes the approach used in the development of a programme of flood risk management measures in Moldova and shows not only the importance of flood potential damages assessments and cost-benefit evaluations but also the need to summarise the results of such assessments and evaluations using few parameters (e.g. 'total risk', 'priority of measure') to assist the decision-making processes.

\section{MASTER PLAN FOR FLOOD RISK MANAGEMENT IN MOLDOVA}

In the framework of European Neighbourhood Policy (ENP) the European Investment Bank, following a request for support from the Ministry of Environment following the 2010 floods, decided to develop a countrywide flood management Master Plan and an Investment Programme, funded by EPTATF (Eastern Partnership Technical Assistance Trust Fund). In order to define this investment programme, BETA Studio srl (Italy) and HR Wallingford Ltd (UK) were appointed to prepare a Master Plan for flood risk management in Moldova. This Master Plan provides a phased investment programme of flood management measures for rivers in Moldova covering a 20-year period and a Short-Term Investment Plan (STIP) covering the next 7 years.

A large proportion of the flood risk in Moldova occurs on the floodplains of the two main rivers (the Prut and the Dniester). There are systems of flood defence dykes on these rivers and some on the tributaries. These provide flood protection but there is a concern about their condition. Flooding also occurs on the tributaries and failure of dams is regarded as a serious potential cause of flooding. Several studies have been carried out in the past related to hydrology and flooding, but there was a lack of a comprehensive study for flood risk assessment (FRA) for the whole country and for the identification of measures to reduce such risk.

The Master Plan was developed in the following main stages: (i) Preliminary Flood Risk Assessment (PFRA) covering all 12,000 km of rivers in Moldova and identification of highrisk areas; (ii) detailed fully two-dimensional hydraulic modelling of the high-risk rivers to produce flood hazard and flood risk maps; (iii) identification of measures to reduce the flood risk; (iv) prioritisation of measures and development of a phased investment programme and an STIP.

\section{FLOOD RISK ASSESSMENT}

The purpose of FRA is to assess the potential adverse consequences of flood scenarios. FRA requires knowledge of the probability of flooding and the consequences of flooding.

The probability of flooding was obtained from the results of a detailed fully two-dimensional hydraulic modelling of the studied rivers (about 3,400 km in the whole of Moldova) for floods with annual exceedance probabilities of $1,0.5$ and $0.1 \%$. The results of the hydraulic modelling included flood hazard maps showing the flood extent and flood depth for each of the modelled flood events. 
The consequences of flooding consist of the impacts of flooding on the 'receptors' (people, buildings, agriculture, infrastructure, etc.). These consequences have been estimated as described in the following sections.

\subsection{Criteria for FRA}

Different consequences of flooding should be taken into account in FRA. The impacts to be considered in this study have been agreed with the local stakeholders. In particular, the following consequences of flood events were discussed: loss of lives and property, loss of livelihoods, environmental damage, health impacts, resettlement away from flood risk areas, psychosocial effects, hindering of economic growth and development and political implications. An open discussion was held with the stakeholders on the basis of these concepts and the chosen criteria agreed with the stakeholders can be grouped into: (i) human impacts; (ii) economic impacts; (iii) environmental impacts.

\subsection{Risk evaluation methodology}

In the project, the main objectives of the risk evaluation methodology were: (i) to identify and map areas of high, medium or low risk; (ii) to calculate damages for the appraisal of flood risk management options.

To do this, some indicators for FRA had to be chosen: these indicators on one hand should be representative of the most important flood consequences and, on the other hand, should be sufficiently simple to be used in an efficient way in the study.

The developed methodology took into account the criteria agreed with the stakeholders, the Floods Directive [7] and a guideline [10] prepared by the European Commission. As a result, 12 different flood risk indicators were considered, grouped in 3 categories of impact as shown in Table 1.

Using the results of hydraulic modelling (flood outlines for the three return periods considered) the value of each flood risk indicator is calculated using raster square grid discretisation (200 m) of the whole Moldova.

The risk indicator HU1, number of affected people, is calculated by intersecting the flooded area with a GIS layer file of the urbanised area, which includes information on population density for each city, town and village in Moldova.

The risk indicators HU2 and HU3, that represent the number of severely and very severely affected people during a flood, respectively, are calculated in a similar way as HU1, but only considering the flooded area where the combination of flood depth $(d)$ and velocity $(v)$ is greater than certain threshold values that can constitute a risk to people, according to the standard matrix used in the UK (Defra [11]).

The last two flood risk indicators for the category 'human impact' represent the impact due to the interruption of critical services: number of water supply points flooded (HU4) and length of key infrastructure flooded (main roads/railways) (HU5).

Economic impacts are calculated using the internationally accepted and most common method for the estimation of direct flood damage that consists of the application of depthdamage functions $[12,13]$. Depth-damage functions represent relationships between flood depth and the resulting monetary damage: for a given flood depth the function gives expected losses to a specific property or land use type, either as a percentage of a pre-defined asset value (relative function) or directly in financial terms (absolute function). The following procedure 
Table 1: Flood risk indicators used in the project.

\begin{tabular}{|c|c|c|c|}
\hline $\begin{array}{l}\text { Categories of } \\
\text { impacts }\end{array}$ & Symbol & Flood risk indicators & Unit \\
\hline \multirow{5}{*}{ Human impacts } & HU1 & Number of affected people & - \\
\hline & HU2 & $\begin{array}{l}\text { Number of severely affected people }(d \cdot(v+0.5))>1.5) \\
\text { where } d \text { is depth of flooding and } v \text { is flow velocity }\end{array}$ & - \\
\hline & HU3 & Number of very severely affected people $(d \cdot(v+0.5))>2.5)$ & - \\
\hline & HU4 & Number of water supply points flooded & - \\
\hline & HU5 & Length of key infrastructure flooded (main roads, railways) & M \\
\hline \multirow{3}{*}{$\begin{array}{l}\text { Economic } \\
\text { impacts }\end{array}$} & $\mathrm{EC} 1$ & Damages for residential area (cities, towns, villages) $[€]$ & $€$ \\
\hline & $\mathrm{EC} 2$ & $\begin{array}{l}\text { Damages for non-residential area (industrial and } \\
\text { commercial) }[€]\end{array}$ & $€$ \\
\hline & EC3 & Agriculture damages $[€]$ & $€$ \\
\hline \multirow{4}{*}{$\begin{array}{l}\text { Environmental } \\
\text { impacts }\end{array}$} & EN1 & Extent of environmental sites flooded & $\mathrm{m}^{2}$ \\
\hline & EN2 & $\mathrm{n}^{\circ}$ of heritage sites flooded & - \\
\hline & EN3 & $\begin{array}{l}\mathrm{n}^{\circ} \text { of pollution sources (WWTP, oil stations, waste disposal } \\
\text { sites ...) flooded }\end{array}$ & - \\
\hline & EN4 & Extent of diffuse source of pollution & $\mathrm{m}^{2}$ \\
\hline
\end{tabular}

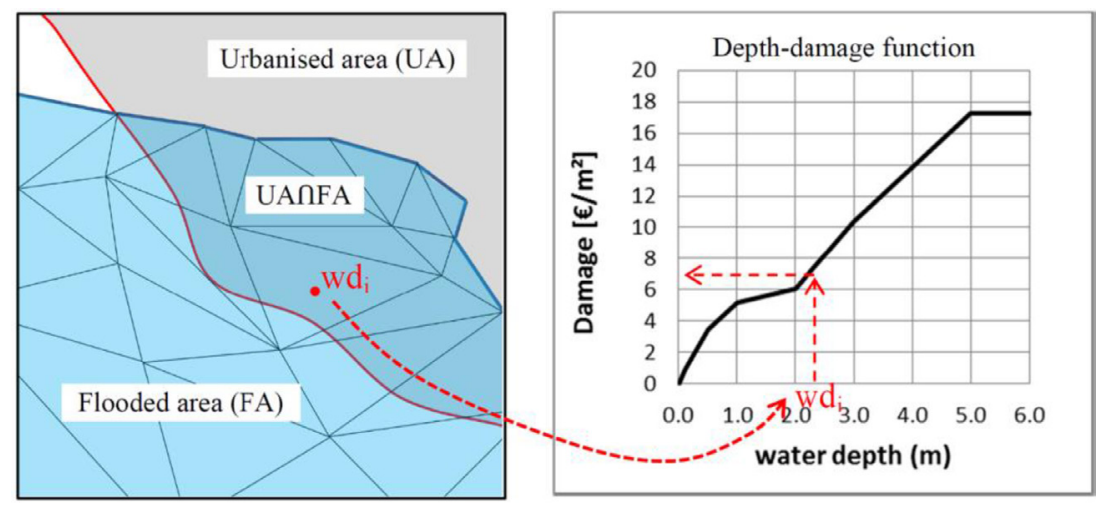

Figure 1: Calculation of damages for residential area.

was applied for EC1 (damages for residential area), for each square grid of the domain (see Fig. 1):

- The flooded area (FA) is intersected with the urbanised area (UA) to obtain the polygon UAกFA. Note that the polygon UAกFA consists of different triangular cells (the hydraulic model mesh) and that three different types of urban area are considered: city, town and village, each with a different damage function; 
- For each triangular cell of UAกFA, the damage value $\left(€ / \mathrm{m}^{2}\right)$ is calculated applying the relevant damage function for the particular urbanised area to the maximum water depth $\left(w d_{i}\right)$ in the cell as calculated by the hydraulic model;

- The damage for each residential area in the grid square $[€]$ is calculated summing, for each triangular cell, the product of the above value and the extent of the triangular cell.

The flood risk indicators EC2 - damages for non-residential area (industrial and commercial) - and EC3 - agriculture damages - have been calculated taking into account the relevant depth-damage functions for those categories. As suggested in studies that compare post-flood damage data with predictions $[14,15]$ caution in transferring and applying damage curves from one country to another should always be used, as transferability depends on (but it is not limited to) the similarity, in terms of flood event and/or building characteristics, between the two countries or regions. For this reason, particular effort was made to construct depth-damage functions that were representative of the characteristics of receptors in Moldova, using local expert judgment and damage data for floods that have occurred in the past.

A basic indicator of the potential flood impacts to the environment is to measure the area of important habitats that are prone to inundation by flooding. As the flooding of an environmental protected area may be a damaging, neutral or even a beneficial event, depending on the particular characteristics of the specific area, an assessment of the vulnerability of environmental sites has been done on a site by site basis. For each site exposed to flood risk, a 'flood vulnerability factor' with a value between 0 and 1 has been evaluated by an environmental expert. Thus, the factor EN1 has been evaluated multiplying the extent of the environmental areas within the flooded area by the 'flood vulnerability factor'.

The flood risk indicator EN2 refers to the number of heritage sites flooded.

When pollution sources are flooded, it is very likely that polluted elements will be washed out by the flood water causing severe environmental problems. The last two considered flood risk indicators EN3 and EN4 take into account of such impacts. In particular, EN3 is the number of pollution sources (including petrol stations, industries, wastewater treatment plants, and sites for the disposal of waste materials) flooded and EN4 refers to the pollution due to flooding of sewage system and is calculated assuming that it is proportional to the extent of the urbanised area.

After having estimated the values of the risk indicators for each return period, each flood risk indicator is 'annualised' to estimate the long-term annual average impacts. For example, the flood risk indicator 'Annual Average Damage' is the estimated average economic damages arising from all sources of flooding which, taken over the very long-term, is likely to occur on an annual basis. Similarly, the 'Annual Average Number of People Affected' is an estimate of the number of people that may be flooded in an average year. This has been done by producing an impact-probability curve. The total area under this curve represents the annualised value of the flood risk indicator or, to put it another way, the long-term average annual value of the flood risk indicator (Fig. 2).

Finally, a unique value of 'total risk' is calculated, adding together the weighted annualised values of flood risk indicators. The final value of 'total risk' is express in $€$, so each weight (equal to 1 for EC1, EC2 and EC3) represents the conversion factor to express each flood risk indicators in economic terms. Even if it is recognised that these conversion factors have a degree of subjectivity, they represent a very efficient way of summarising all the different 


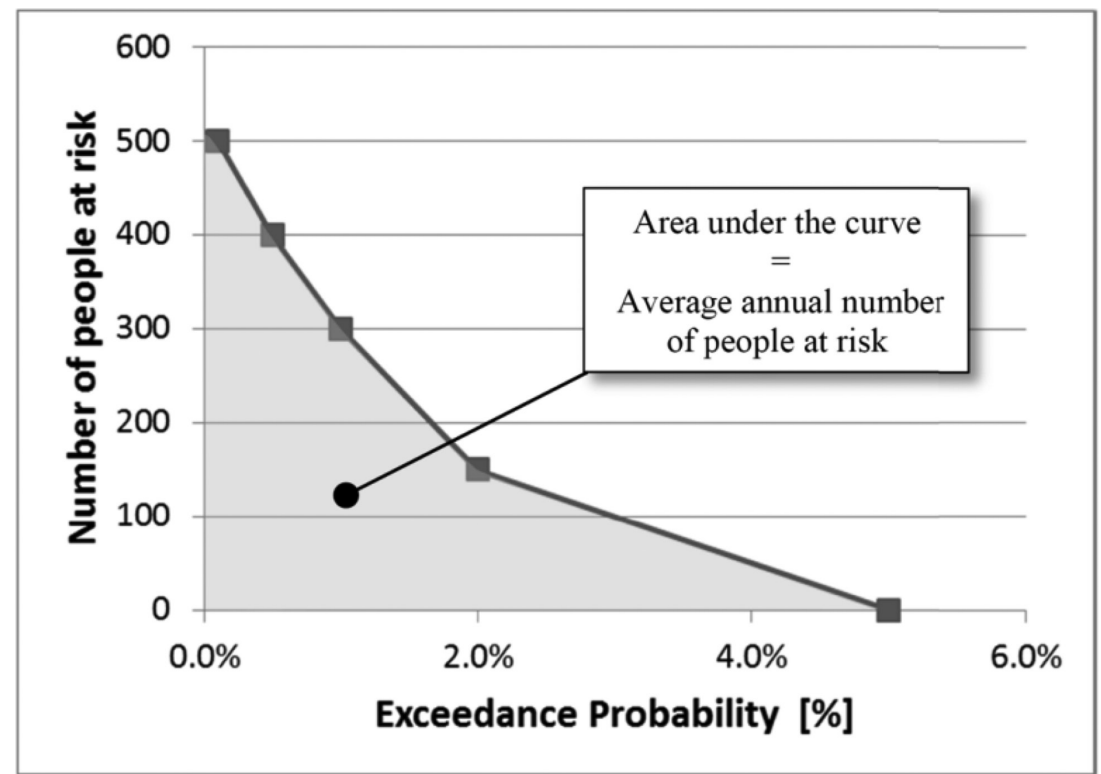

Figure 2: Calculating annual average values (annualisation).

Table 2: Levels of risk showed in the flood risk maps.

\begin{tabular}{lc}
\hline Total risk in the cell [€/year] & Level of risk \\
\hline $0-250$ & Low \\
$250-2,500$ & Medium \\
$2,500-25,000$ & High \\
$>25,000$ & Very high \\
\hline
\end{tabular}

flood impacts in a unique value, the 'total risk'. This has been very useful for identifying the areas with the greatest risk and to assist the decision-making processes.

\subsection{Results obtained}

On the basis of the FRA conducted, flood risk maps have been prepared showing the different levels of risk (low, medium, high and very high), with respect to the value of the 'total risk' computed as described in the previous section (see Table 2). This clearly shows the areas where the flood risk is greatest and therefore the areas where flood risk management measures are most likely to be required (Fig. 3).

The total annual flood risk for the $3,400 \mathrm{~km}$ of studied rivers in Moldova was estimated to be $€ 56$ million. Almost half is due to direct economic damages (EN1+EN2+EN3) and the remainder is due to indirect damages including human and environmental impacts. The average annual number of people affected by flooding was estimated to be 5,200 of which $44 \%$ would be severely affected and $15 \%$ very severely affected. 


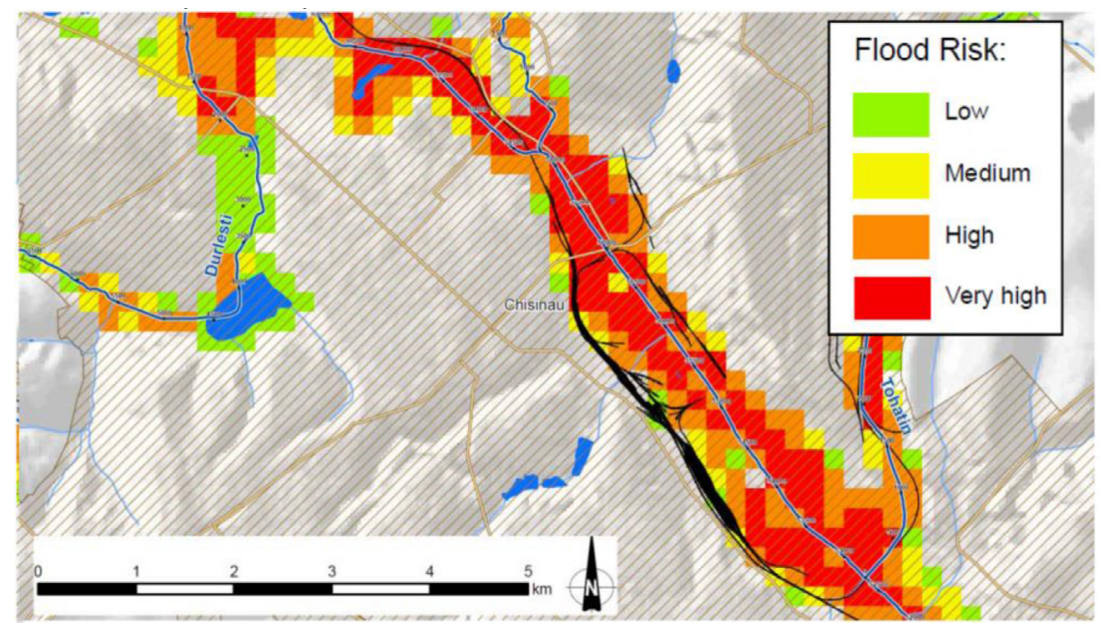

Figure 3: Example of flood risk map.

\section{PRIORITISATION OF MEASURES}

\subsection{Objective of prioritisation}

Flood management measures were identified for the areas with the greatest flood risk including both structural and non-structural measures. Flood risk is widespread on the rivers in Moldova and a total of 84 structural measures were defined to reduce flood risk for over 100 settlements. The total cost of these measures is $€ 325$ million.

As funding is limited, it was necessary to decide which measures are better to implement first: a method for prioritisation of measures was therefore needed.

\subsection{Method for prioritising the measures}

A method for prioritising the measures has been discussed and agreed with local stakeholders. The method for prioritisation takes account of:

- The urgency of the measure;

- The magnitude of the risk that can be reduced with the measure;

- The benefit-cost ratio of the measure.

\subsubsection{Urgency of measures}

The urgency takes into account the need to develop the measure as soon as possible and includes:

- Dykes that are in poor condition and require urgent repair;

- Measures to protect urbanised areas that have been affected by flood events in the past.

The dykes that are in poor condition have been identified during a specific survey conducted as part of project activities, while urbanised areas affected by floods events 
in the past have been identified on the basis of data collected during the first part of the assignment.

The urgency of measures has been defined on the basis of the above criteria as shown in Table 3.

\subsubsection{Magnitude of the risk that can be reduced}

The magnitude of the risk that can be reduced with the measure has been calculated on the basis of the number of people that can be protected by the particular measure: the greater the number of people protected, the higher the priority of the measure, as shown in Table 4. The number of people protected has been evaluated for each measure for the $1 \%$ flood event, calculating the difference between the value of flood risk indicator HU1 'Number of people affected' (see Section 3.2) at present with the value of HU1 with the measure implemented.

\subsubsection{Benefit-cost ratio}

A third indicator used to assign the priority of each measure is the benefit-cost ratio of each measure: a measure with a low cost and high benefit would have a high priority. In particular, the benefit-cost ratio $(B C R)$ has been calculated as:

$$
B C R=(B \cdot 20) /(C i+C m \cdot 20)
$$

where:

- $B$ is the benefit of the proposed measure [€/y] and is calculated as the difference between the annualised risk at present and the annualised risk with the measure implemented;

- $\mathrm{Ci}$ is the cost of implementation of the measure [€];

- $\mathrm{Cm}$ is the maintenance cost of the measure [€/year].

Depending to the value of BCR the priority for the benefit/cost criterion is shown in Table 5.

Table 3: Priority of a measure according to its urgency.

Does the measure defend an area that Defences in poor condition that has been flooded in the past? require urgent repair?

Urgency priority

\begin{tabular}{lcc}
\hline Yes & Yes & High \\
Yes & No & Medium \\
No & Yes & Medium \\
No & No & Low \\
\hline
\end{tabular}

Table 4: Priority of a measure according to the magnitude of the risk that can be reduced with the measure.

\begin{tabular}{lc}
\hline No. of people protected with the measure & Magnitude of risk reduction priority \\
\hline $0-200$ & Low \\
$200-1000$ & Medium \\
$>1000$ & High \\
\hline
\end{tabular}


Table 5: Priority of a measure according to its benefit/cost ratio.

\begin{tabular}{lc}
\hline BCR & Benefit/cost priority \\
\hline $0-1$ & Low \\
$1-2$ & Medium \\
$>2$ & High \\
\hline
\end{tabular}

Table 6: Priority of a measure.

Total score (sum of urgency, magnitude and benefit-cost scores)

Priority of the measure

\begin{tabular}{lc}
\hline 3,4 & Low \\
5 & Medium \\
6,7 & High \\
8,9 & Very High \\
\hline
\end{tabular}

\subsubsection{Total priority}

The total priority of each measure has been assigned in the following way: for each measure and for each one of the three criteria (urgency, magnitude and benefit-cost) scores ranging from 3 to 1 have been assigned ( 3 for High, 2 for Medium and 1 for Low) and these are summed to give the total score for each measure. The priority of the measure has been assigned according to the value of score in Table 6.

The above methodology for prioritisation of measures has been applied both to structural and non-structural measures. In the case of non-structural measures the level (low, medium, high) of urgency, of magnitude of protected people and potential benefits that can be achieved in comparison to the costs of the measure have been based on the judgment of experts and agreed with the relevant stakeholders.

\section{CONCLUSIONS}

Despite the growing importance that appraising, prioritising and financing flood risk management measures is gaining in flood risk management, most of the tools needed (including damage modelling, cost-benefit analysis) can still be considered as a relatively new research area compared to other water resources fields such as hydrologic and hydraulic modelling. The methodologies that are used are not standardised, and the results are affected by large uncertainties.

This paper describes methodologies for FRA and prioritisation of measures that have been developed and applied as part of the development of a national programme of flood risk management measures in Moldova.

These methodologies proved to be valuables tools for the identification of areas with the highest flood risk, for comparing different flood risk management options and for selecting the most appropriate measures, based on an assessment of flood risks under present conditions and with the measures to reduce the flood risks in place. In particular, the final result of the FRA provides values of the parameter 'total risk' in a $200 \mathrm{~m}$ square grid for all high-risk rivers in the whole country that summarizes the consequences of floods with different annual 
exceedance probabilities on different receptors (including economy, human health, the environment and cultural heritage).

Once these relatively complex and comprehensive methodologies had been explained and agreed with the stakeholders, the simple way in which the results of the FRA and measures appraisal and prioritisation were presented facilitated the discussion with the same stakeholders and agreement of the decision-making process.

\section{REFERENCES}

[1] UNISDR, Global Assessment Report on Disaster Risk Reduction - Revealing Risk, Redefining Development, United Nations: Geneva, 2011.

[2] Environment Agency, The Costs of the Summer 2007 Floods in England, Environment Agency: Bristol, SC070039/R1, 2010.

[3] ADB \& The World Bank: Pakistan floods 2010: Preliminary damage and needs assessment, Asian Development Bank: Islamabad, 2010.

[4] Smith, K. \& Ward, R., Floods: Physical Processes and Human Impacts, John Wiley and Sons: Chichester, 1998.

[5] Jonkman, S.N., Bockarjova, M., Kok, M. \& Bernardini, P., Integrated hydrodynamic and economic modelling of flood damage in the Netherlands. Ecological Economics, 66, pp. 77-90, 2008. http://dx.doi.org/10.1016/j.ecolecon.2007.12.022

[6] Meyer, V., Becker, N., Markantonis, V., Schwarze, R., van den Bergh, J.C.J.M., Bouwer, L.M., Bubeck, P., Ciavola, P., Genovese, E., Green, C., Hallegatte, S., Kreibich, H., Lequeux, Q., Logar, I., Papyrakis, E., Pfurtscheller, C., Poussin, J., Przyluski, V., Thieken, A.H. \& Viavattene, C., Assessing the costs of natural hazards - state of the art and knowledge gaps. Natural Hazards and Earth System Science, 13, pp. 1351-1373, 2013. http://dx.doi.org/10.5194/nhess-13-1351-2013

[7] European Commission, EU Directive on the estimation and management of flood risks (EU/60/2007), 2007.

[8] Plate, E.J., Flood risk and flood management. Journal of Hydrology, 267, pp. 2-11, 2002. http://dx.doi.org/10.1016/S0022-1694(02)00135-X

[9] Sayers, P.B., Hall, J.W. \& Meadowcroft, I.C., Towards risk-based flood hazard management in the UK. Civil Engineering, 150(5), pp. 6-42, 2002.

http://dx.doi.org/10.1680/cien.2002.150.5.36

[10] European Commission, Risk Assessment and Mapping Guidelines for Disaster Management, Commission Staff Working Paper: Brussels, 21.12.2010, SEC (2010) 1626 final, 2010.

[11] HR Wallingford, Flood Hazard Research Centre (Middlesex University) \& Risk \& Policy Analysts Ltd, Flood and Coastal Defence R\&D Programme: Flood Risks to People Phase 2, Defra \& Environment Agency: London, 2006.

[12] Smith, D.I., Flood damage estimation - a review of urban stage-damage curves and loss functions. Water SA, 20, pp. 231-238, 1994.

[13] Fattorelli, S. \& Frank, E., A distributed technique for flood damage assessment using GIS and a 2D hydraulic model. River Basin Management III, pp. 433-442, 2005.

[14] Scorzini, A.R. \& Frank, E., Flood damage curves: new insights from the 2010 flood in Veneto, Italy. Journal of Flood Risk Management, 2015. http://dx.doi.org/10.1111/jfr3.12163

[15] Jongman, B., Kreibich, H., Apel, H., Barredo, J.I., Bates, P.D., Feyen, L., Gericke, A., Neal, J., Aerts, J.C.J.H. \& Ward, P.J., Comparative flood damage model assessment: towards a European approach. Natural Hazards Earth System Science, 12, pp. 3733-3752, 2012. http://dx.doi.org/10.5194/nhess-12-3733-2012 